\title{
Work Accommodations and Natural Supports for Employees with Severe Mental Illness in Social Businesses: An International Comparison
}

Patrizia Villotti, $1{ }^{*}$

Email Patrizia.Villotti@usherbrooke.ca

Marc Corbière, 2,3

Ellie Fossey, 4,5

Franco Fraccaroli, 6

Tania Lecomte, ${ }^{3,7}$

Carol Harvey, 5

1 Centre de recherche de l'Hôpital Charles LeMoyne, Université de Sherbrooke, Longueuil, QC, J4K 0A8 Canada

2 Department of Education, Career Counselling, Université du Québec à Montréal (UQAM), Montreal, Canada

3 Centre de Recherche de l'Institut Universitaire en Santé Mentale de Montréal (CRIUSMM), Montreal, Canada

4 Department of Occupational Therapy, School of Primary Health Care, Monash University, Clayton, Canada

5 Psychosocial Research Centre, Department of Psychiatry, University of Melbourne, Parkville, Australia

6 Department of Psychology and Cognitive Science, University of Trento, Trento, Italy

7 Department of Psychology, University of Montreal, Montreal, Canada 


\section{Abstract}

Little is known about the types of work accommodations and natural supports that are useful for people experiencing severe mental illness working in social businesses. We conducted an exploratory, descriptive and cross-sectional investigation in Australia, Canada and Italy to study the nature of work accommodations and natural supports available in social businesses. Study findings are drawn from survey responses of a convenience sample of 90 employees with self-reported psychiatric disabilities. Results showed that, regardless of the country, social businesses provide many work accommodations and natural supports, especially those linked to schedule flexibility and support, while work accommodations related to training and schedule flexibility were linked to longer job tenure. Overall, this study advances our knowledge about the spectrum of work accommodations and natural supports that are available in social businesses for people with severe mental illness. Also, it highlights the type of work accommodations that are likely to support this population to sustain employment.

$\mathrm{AQ}_{1} \Omega$

\section{Keywords}

Work participation

Work accommodations

Natural supports

Mental illness

Social business

\section{Introduction}

Employment is a human right, important socially and economically, and plays a critical role in the recovery of people experiencing severe mental illnesses such as schizophrenia, bipolar disorder, and major depression (Kirsh et al. 2005 ; Mueser and McGurk 2014). Unemployment rates in this population are unfortunately much higher than those of the general population and any other group of people with disabilities (Baldwin and Marcus 2011). Furthermore, those who are working tend to have poor job retention: job tenure for this population is indeed often brief, usually $<1$ year (Corbière et al. 2006; Lanctôt et al. 2013). Therefore, their work 
integration-defined as entering the labor market and being able to maintain employment over time - remains a challenge. Yet, given appropriate opportunities and support, individuals with severe mental illness can get and keep work (Frado 1993: Schultz et al. 2011).

Several authors suggest that social businesses are useful settings to respond to the employment needs of people with severe mental illness (Corbière and Lecomte 2009; Svanberg et al. 2010; Zaniboni et al. 2011). Social businesses were created specifically to provide employment and career opportunities for people who are disadvantaged in the labor market. The idea of social business has a long history around the world: the first ones were established in the form of social cooperatives in Italy during the 1970s, with the specific aim of creating job opportunities for individuals reintegrating into society following deinstitutionalization (Borzaga and Santuari 2000). This new form of business was recognized by the Italian law during the 1990s with the name of B-type social cooperatives. Since then these businesses have spread worldwide, including to Canada where the term 'Social Enterprise' describes private organizations with the aims of producing goods and/or services and creating innovative solutions to exclusion and unemployment (D'Amours 2002). In Australia the first social businesses, known as social firms, were established ten years ago to create durable employment for people with mental illness (Paluch et al. 2012). Thus, across countries, social businesses may differ in name but are characterized by the same social and economic intentions. They aim to employ a significant proportion of workers who experience disability or other disadvantages, and pay a market-rate wage or salary appropriate to the work. Social businesses provide supportive and flexible work environments characterized by better accommodations and less discrimination towards people with mental illness, while also promoting a sense of belonging, success, and competence (Lanctôt et al. 2012; Svanberg et al. 2010). These features distinguish social businesses from other vocational rehabilitation programs (Villotti et al. 2014). While social businesses can be linked to different types of economic activity (e.g., training, gardening, home maintenance), all social businesses that took part in the present study operated cleaning services.

Employment is not inherently beneficial: workplaces can be stressful as well as supportive (Broom et al. 2006). The vocational success of people with severe mental illness is typically characterized by a positive fit between the worker's employment interests and skills, the tasks, and the workplace (Kirsh 2000; Leufstadius et al. 2009). The importance of this best fit between persons and 
environments emphasizes the need to attend to barriers in the environment and contextual accommodations, so as to promote social integration of employees with severe mental illness with their co-workers (Kirsh 2000; Roulstone and Warren 2005; Vanhala 2006; Wehman 2003 ). Work accommodation can be defined as any modification or adjustment to the workplace or workplace procedures, which allows a person with special needs to perform the tasks required (Frado 1993). Some workplaces have inherent features that are per se supportive for people with special needs. Referred to as natural support, this includes human or technical resources (such as supports at the organizational, physical, social, training, services and community levels) that are readily available in the workplace to facilitate integration, acceptance, and satisfaction, and to promote the goals and interests of workers and employers (Corbière et al. 2014a). The implementation of work accommodations, when insufficient natural supports are present in the workplace, is a key factor for maximizing the capabilities of persons experiencing disabilities to participate in the workforce (MacDonald-Wilson et al. 2002; Williams et al. 2006). They are also a vital lever for: creating a better fit between job characteristics and workers' interests and capabilities; maintaining jobs (Corbière et al. 2014a; Williams et al. 2016); increasing workplace productivity (Solovieva et al. 2011); and enhancing job satisfaction (Villotti et al. 2012). AQ3 $\square$

Most work accommodations described in the literature concern employees with physical rather than psychiatric disabilities (MacDonald-Wilson et al. 2002, 2003 ). Indeed, the work accommodations needed by employees with physical impairments are relatively well understood and easily identifiable, whereas the accommodation needs of people with psychiatric disabilities are often more hidden and ambiguous. This brings unique challenges for employees, employers and unions alike (Payne 2005 ). Until recently there were few descriptions and little empirical data about the types of work accommodations that may be useful for people experiencing severe mental illness (Corbière et al. 2014a; McDowell and Fossey 2014). Indeed, this paucity of information is particularly problematic within the social business context given their explicit objective to provide flexible and supportive workplaces.

The aim of the present study is to learn more about the nature, and the link to job tenure, of workplace accommodations and natural supports for employees with severe mental illness in social businesses operating in three different countries: Australia, Canada and Italy. These countries were selected among others because of the above mentioned history of development of social business. These betweencountry comparisons will allow us to generalize (or not) the types of workplace 
accommodations and natural supports provided in social businesses to workers with severe mental illnesses, and their usefulness in term of job tenure. Indeed, alongside the description of the availability of certain types of work accommodations offered to people with severe mental illness in the context of social businesses, we aim to highlight the work accommodations and natural supports that are the most helpful for maintaining employment in this vulnerable population of workers, regardless of the country studied.

\section{Methods}

\section{Procedure and Participants}

Three sets of data were used in this study to analyze and compare the implementation of work accommodations and natural supports in social businesses in the targeted countries (i.e., Australia, Canada and Italy). The first dataset was collected from a convenience sample of employees in three social businesses operating in Melbourne, Australia in 2013. In parallel, the second dataset was collected from employees working in social businesses in Montreal, Canada. Because social businesses in Australia and Canada are fairly recent developments, social businesses in these two locations were contacted one by one until a satisfactory number of participants were recruited. The social businesses were contacted through telephone, or personal meetings, and informed about the purposes of the study. The criteria used to identify potential participants in Melbourne and Montreal were: (1) employed in a social business operating a cleaning service, and (2) self-reported psychiatric disorder. The third dataset used for this paper stems from a larger, longitudinal study of B-type social cooperatives in northern Italy conducted in 2011 (see Zaniboni et al. 2011; Villotti et al. 2012). Recruitment criteria were similar to that described above. This larger Italian dataset allowed us to select individuals with similar socio-demographic (i.e., age, gender, diagnosis) and employment characteristics (i.e., being employed in social businesses operating a cleaning service) to those in the Australian and Canadian samples. Ethical approvals from the ethic committees of the University of Trento (Italy), Université de Sherbrooke (Canada) and University of Melbourne (Australia) were obtained prior to commencement of the studies in each of these countries. In the Australian study, questionnaires were distributed to employees for anonymous completion and return via mail; they were informed that consent would be implied by the return of completed questionnaires. In the Canadian and Italian studies, participants were self-selected: first, social businesses were approached by phone calls, emails, or in person meetings; subsequently, employers informed employees 
about the study, and those interested in participating filled out the written informed consent and the questionnaire. Participants from Italy and Canada received compensation for their time.

The total study sample consisted of 90 employees with self-reported psychiatric disabilities in social businesses located in Australia $(\mathrm{N}=30)$, Canada $(\mathrm{N}=30)$ and Italy $(\mathrm{N}=30)$.

\section{Measures}

Participants completed a survey consisting of: socio-demographic details to characterize participants' age, gender, education, marital status, employment status, and length of work in the social business. To collect information about the type and nature of work accommodations available inside social businesses, we asked participants to complete the Work Accommodation and Natural Support Scale (WANSS, Corbière et al. 2014a). The WANSS, developed to investigate the implementation of workplace accommodations and natural supports in the regular labor market, consists of 40 items spread over 6 subscales: "Support from different stakeholders"; "Presence of job-coach in the work environment"; "Supervisor and Co-worker supports"; "Training"; "Schedule flexibility"; "Work environment". Items are dichotomous with possible answers as follows: 0 (no, this accommodation is not available at my workplace) and 1 (yes, this accommodation is available at my workplace). The WANSS has been validated for people with severe mental disorders recently obtaining employment by Corbière and colleagues (2014a).

\section{Data Analysis}

For the purpose of this study, one WANSS subscale, namely "Presence of job coach in the work environment" ( 3 items, i.e. "Was your employment specialist present when you were hired?", "Does your employment specialist visit you on the job?", "Are there meetings with your employment specialist, your supervisor and yourself?") and one item from the Support from different stakeholders subscale (i.e., "Do you have phone access to your employment specialist during working hours?") were excluded in the analyses, because these items were not pertinent in the specific context of social businesses or the sector of activity. More specifically, a job coach is not always present in social businesses and is more common in settings where supported employment programs are well implemented, such as in Canada (Corbière et al. 2010, 2014a). To describe the work accommodations and natural supports offered in the context of social businesses across different countries, we looked at the percentage of participants who answered 'yes' to the 
WANSS question: 'Is this accommodation/support available at your workplace?'. Because the assumption of normality was violated by our data, we used the nonparametric Kruskal-Wallis test and post hoc comparisons using the Mann-Whitney tests to study differences between participants' responses in the three countries on the WANSS total score and subscale scores (except "Presence of job-coach in the work environment" as noted above). A Bonferroni correction was applied and so all effects are reported at a 0.0167 level of significance. Finally, a regression analysis for all samples $(n=90)$, was conducted to estimate job tenure in the context of social business, by considering socio-demographic variables (i.e., gender, age, diagnosis, level of education and marital status - selection of variables based on the literature review of Tsang et al. 2010 and; Wewiorski and Fabian 2004), the country of origin, and WANSS subscales. The statistical analyses were performed using SPSS for Windows, release 21.

\section{Results}

Participants in the study were generally male (73.3\% in the Australian and Canadian subsamples; $70 \%$ in the Italian one), middle-aged (Australia: $\mathrm{M}=43.79$ years, $\mathrm{SD}=9.52$; Canada: $\mathrm{M}=45.80$ years, $\mathrm{SD}=8.27$; Italy: $\mathrm{M}=44.17$ years, $\mathrm{SD}$ $=5.08$ ), single (Australia 86.7\%; Canada 93.3\%; Italy 80\%) and poorly educated (i.e., secondary school qualification or less; Australia 53.6\%, Canada 56.7\%, Italy $40 \%$ ). As for the diagnosis, the majority of participants reported a diagnosis of schizophrenia (64.3\% in the Australian subsample; $40 \%$ in the Canadian subsample; $46.7 \%$ in the Italian subsample), followed by mood disorders (i.e., major depression, bipolar disorder; $17.9 \%$ in the Australian subsample; $46.7 \%$ in the Canadian subsample; $33.3 \%$ in the Italian subsample), and personality disorders (17.8\% in the Australian subsample; $13.3 \%$ in the Canadian subsample; $20 \%$ in the Italian subsample).

Regarding participants' characteristics, there were no statistically significant differences among the three groups, based on country of origin, for sociodemographic variables (i.e., age, gender, diagnosis, marital status, level of education). Significant differences emerged between groups for variables related to employment status (i.e., length of job tenure, hours worked per week). Job tenure (months) was significantly $[\mathrm{F}(2,87)=3.18, p=.047]$ greater in social businesses located in Italy $(\mathrm{M}=88.66, \mathrm{SD}=57.82)$ compared to those located in Canada $(\mathrm{M}=$ $70.72, \mathrm{SD}=61.84)$ and Australia $(\mathrm{M}=51.57, \mathrm{SD}=47.50)$. Significant differences $[F(2,87)=76.29, p=.000]$ emerged for the amount of hours worked per week, with Canadian workers reporting a higher number of hours $(\mathrm{M}=33.48, \mathrm{SD}=6.46)$ 
compared to Italian $(\mathrm{M}=21.27, \mathrm{SD}=8.47)$ and Australian $(\mathrm{M}=11.83, \mathrm{SD}=11.83)$ employees. In almost all cases participants in the study from each country were working part time, meaning less than $35 \mathrm{~h}$ per week.

Descriptive analyses showed that the provision of work accommodations and natural supports is generally high in social businesses (on a scale from 0 to 36, Australia: $\mathrm{M}=25.80, \mathrm{SD}=6.26$; Canada: $\mathrm{M}=24.04, \mathrm{SD}=6.00$; Italy: $\mathrm{M}=22.62$, $\mathrm{SD}=5.58)$. The most commonly implemented types of accommodation in each country were related to schedule flexibility (e.g., "Are you able to have time off for clinic/medical appointments?") (on a scale from 0 to 4 , Australia: $\mathrm{M}=3.45, \mathrm{SD}=$ 1.38; Canada: $\mathrm{M}=3.22, \mathrm{SD}=1.30$ ); Italy: $\mathrm{M}=3.30, \mathrm{SD}=1.28$ ) and support from supervisor and coworkers (e.g., "Do your coworkers or supervisor take time in order to assist/orient you?") (on a scale from 0 to 12 , Australia: $\mathrm{M}=9.31, \mathrm{SD}=$ 1.89; Canada: $\mathrm{M}=9.34, \mathrm{SD}=2.06$ ); Italy: $\mathrm{M}=7.80, \mathrm{SD}=2.26$ ). Less commonly implemented types concerned the physical work environment (e.g., "Are you able to change the lighting?") (on a scale from 0 to 7 , Australia: $\mathrm{M}=2.64, \mathrm{SD}=1.48$; Canada: $\mathrm{M}=2.53, \mathrm{SD}=1.34)$; Italy: $\mathrm{M}=2.37, \mathrm{SD}=1.75)$. Work accommodations related to the support from different stakeholders (e.g., "Are you provided with a mentor?") and training (e.g., "Are your tasks introduced gradually?") were moderately implemented (Support from different stakeholders, on a scale from 0 to 5; Australia, $\mathrm{M}=3.69, \mathrm{SD}=1.16$; Canada, $\mathrm{M}=3.46, \mathrm{SD}=1.46$; Italy, $\mathrm{M}=3.03$, $\mathrm{SD}=1.29$; Training, on a scale from 0 to 8 ; Australia, $\mathrm{M}=5.75, \mathrm{SD}=2.32$; Canada, $\mathrm{M}=4.02, \mathrm{SD}=2.07$; Italy, $\mathrm{M}=4.71, \mathrm{SD}=1.87$ ).

Results from the Kruskal-Wallis test showed statistically significant differences among countries limited to the "Supervisor and coworkers supports" $[\mathrm{H}(2)=10.06$, $p=.007]$ and "Training" $[\mathrm{H}(2)=10.79, \mathrm{p}=.005]$ subscales of the WANSS. Posthoc Mann-Whitney tests indicated that the score for Italy (Median $=8.00$ ) for the "Supervisor and coworkers supports" subscale was significantly lower than the score for Canada (Median $=10.00$ ) and Australia (Median $=9.91), \mathrm{U}=268.00, z=$ $-2.685, p=.007$ and $\mathrm{U}=262.00, z=-2.789, p=.005$ respectively, while the score for Canada (Median $=4.00$ ) for the "Training" subscale was significantly lower than the score for Australia (Median =6.76), $\mathrm{U}=248.50, z=-2.995, p=.003$. No main group effect emerged for the other subscales or for the total number of work accommodations and natural supports available in social businesses.

To analyze job tenure in social businesses, a multiple regression analysis was carried out on the full sample $(\mathrm{N}=90)$. A model was tested including: the number of months worked in the social business (i.e. job tenure) as the dependent variable; 
scores on the WANSS scale as predictors of the outcome; and individual characteristics (i.e. gender, age, education, diagnosis, marital status and country of origin) as control variables. On the basis of the study recently conducted by Corbière and colleagues (2014a), we hypothesized that higher levels of ratings on the WANSS scale would yield longer job tenure. A significant regression equation was found $[\mathrm{F}(13,70)=2.086, p=.026]$. The relationships observed between the variables taken into account in the model, were in line with the expectations. In particular, results suggested that job tenure corresponds to higher ratings on two specific WANSS subscales: "Training" $(\beta=0.559, p=.017)$ and "Schedule flexibility" ( $\beta=0.315, p=.024)$. As for the control variables included in the model, older age $(\beta=0.237, p=.034)$ and country of origin (Australia vs others; $\beta=$ $-0.329, p=.010$ ) were the only socio-demographic variables found to be significant predictors of longer job tenure. The predictors included in the model accounted for around $28 \%$ of the variance in job tenure $\left(R^{2}=0.279\right)$.

\section{Discussion}

Social businesses are a valid alternative to other vocational services to improve employment outcomes in people with severe mental illness. This international study was designed to provide new information about the nature of work accommodations and natural supports provided to people with severe mental illness within social businesses across three countries. Natural support and work accommodations are promising yet relatively understudied approaches to improving employment outcomes for individuals with mental illnesses (Williams et al. 2016). Despite a growing literature showing that social businesses enable the work integration of people with severe mental illness by providing workplaces that are supportive and less discriminatory (Paluch et al. 2012; Villotti et al. 2014; Williams et al. 2012), currently there are no published guidelines regarding the provision of job accommodations for people with severe mental illness. This study contributes to better understanding which workplace accommodations and natural supports are likely to support longer job tenure.

Our results showed that many work accommodations and natural supports were available to employees with mental illness in social businesses, regardless of the country in which the businesses were located (on average, from 22.62 to 25.80 on a maximum of 36 as measured by the WANSS). Descriptive analyses showed that these work accommodations and natural supports were especially linked to schedule flexibility and support from supervisor, co-workers and other stakeholders, such as family and friends. This is broadly consistent with McDowell 
and Fossey's (2014) scoping review findings concerning the most commonly available accommodations for this population, albeit within a wider range of vocational services, such as supported employment programs. Furthermore, our regression analyses highlight the crucial role played by schedule flexibility and training in helping people with mental illness to maintain employment. Similarly, these types of workplace accommodations and supports are reported elsewhere as efficient strategies for staying well at work and maintaining employment over time (Corbière et al. 2014a; Fossey and Harvey 2010; Williams et al. 2012, 2016). The least implemented category of work accommodations reported by participants in our study concerns the physical work environment, such as having the opportunity to work from home, having the chance to change and/or reduce noise and lighting. This is understandable since these types of accommodations may be more difficult to implement in social businesses such as those in our study which operate in the cleaning sector (often outside regular work-hours).

Results of the regression analysis in this study revealed no impact of sociodemographic characteristics (educational levels, marital status and diagnosis) on length of job tenure, with the exception of age. Low levels of education, older age, being single and psychiatric symptoms have been reported as negatively linked to obtaining a job (Razzano et al. 2005; Tsang et al. 2010). Further, younger age is associated with better employment outcomes, including maintaining a job (e.g., Mueser et al. 2001). Despite this, older age was found to be a significant predictor of longer job tenure in our sample. This could be understood in several ways: it may reflect workforce stability in social businesses (Williams et al. 2010); a better fit between these business and older workers; or cleaning work may particularly suit older workers.

Differences among countries highlighted in the present study may reflect the longer tradition of social businesses in Italy, as well as the beginnings of social firms in Australia. More training was reported by Australian participants, which may be related to the novelty of social business in the country, and to their average shorter job tenure. In line with this speculation, Italian participants, who reported longer tenure compared to the other two subsamples, may be less in need of close support from supervisor and/or coworkers, as an effect of longer exposure to the working tasks. However, the length of job tenure reported by participants in each country is longer (i.e., more than 1 year) than the general duration of employment reported for this population enrolled in traditional vocational services (Tsang et al. 2002) or in supported employment programs (Bond and Kukla 2011). Although not assessed, it is possible that the managerial style of Italian social businesses differs from that of 
the Canadian and Australian social businesses, and could also have contributed to differences in job tenure.

Understanding how to accommodate at work a person who experiences a severe mental illness is challenging, because his/her needs can appear less obvious and may be more complex compared with those of people with physical impairments. To our knowledge, except for rare studies on the implementation of most common work accommodations (Canadian Mental Health Association 2002), there are no guidelines available, or specific laws that employers can consult, in order to get information on how to accommodate or how to modify the job to support an employee with a mental illness in successfully performing work tasks. Consistent with McDowell and Fossey (2014), the results from our study show that it is less a matter of organizing the work environment by removing physical barriers, or by providing ergonomic chairs or re-arranging the spaces at work, but rather offering human resources management within the organization (i.e. taking time to assist, orient, and support employees with mental illness; providing tailored training, appropriate feedback and flexible working schedules). This also suggests that other staff (e.g., co-workers, supervisors) should be involved in assisting co-workers, and this can be achieved through enhanced workplace knowledge about how to support employees with mental illness (Paluch et al. 2012). It is noteworthy that most accommodations described in this study are far more likely to be available to those employees who disclose their mental illness. Yet deciding whether or not to disclose presents dilemmas for people with mental illness because of fears of being stigmatized and risks of discrimination (Corbière et al. 2014c). This issue is mitigated in social businesses which are typically designed to be disclosurefriendly (Paluch et al. 2012).

Some limitations of this study should be mentioned. Most notably, larger samples of participants from a wider range of social businesses would allow for greater generalization of the results. In particular, the present study only considers one type of business activity (i.e., cleaning services), which reduced the possibility to examine the spectrum of work accommodations available in different types of social businesses. The study data are also cross-sectional, so that the direction of the effects is undetermined. Adding follow-up measures would also permit better prediction of work outcomes. Additionally, participants were significantly different on job tenure between countries and this might have influenced the study results. Also, we lack some information regarding participants' working positions, as well as their severity of symptoms; this information would have provided us with helpful insight in interpreting the results. In this regard, negative symptoms and 
cognitive or sensory processing issues could adversely impact work performance, meaning that workers with these difficulties may need more workplace accommodations (McGurk et al. 2003). Further research should take these variables into account. Lastly, the WANSS data were self-reported by employees, and reliant on their knowledge of the available workplace-based supports. To enhance understanding of these findings, questionnaires eliciting other viewpoints, such as those of the employers and work supervisors, would be useful in future studies of work accommodations and supports.

Despite its limitations, this study advances our knowledge about the spectrum of work accommodations and natural supports that are available in social businesses for people with severe mental illness, and it provides some evidence in explaining longer job tenure for this vulnerable population of workers. In sum, social businesses operating in the three participating countries offer workplaces characterized by flexibility, opportunities for training, support and feedback from the supervisor and co-workers. Given the importance of work in terms of recovery and social inclusion, more studies such as this are needed to truly understand work accommodations and supports for people with severe mental illnesses. The experience learned from the context of social businesses might then be more broadly used, for instance, by employment specialists to offer advice and support as needed to job-seekers and employees with severe mental illness in other sectors of the labor market (Corbière et al. 2014b). To conclude, this cross-sectional analysis of the nature of workplace accommodations and natural supports provided by social businesses in Australia, Canada and Italy helps to enrich our knowledge of the best ways to support the work integration of people with severe mental illness.

\section{Acknowledgements}

This work was supported by the Work Disability Prevention Canadian Institutes of Health Research (CIHR) Strategic Training Program Grant (FRN: 53909).

\section{Compliance with Ethical Standards}

Informed Consent All procedures followed were in accordance with the ethical standards of the responsible committee on human experimentation (University of Trento, Italy; Universitè de Sherbrooke, Canada; University of Melbourne, Australia) and with the Helsinki Declaration of 1975, as revised in 2000 (5). Informed consent was obtained from all individual participants included in the study. 


\section{References}

Baldwin, M., \& Marcus, S. (2011). Stigma, discrimination, and employment outcomes among persons with mental health disabilities. In I. Schultz \& E. Rogers (Eds.), Work accommodation and retention in mental health (pp. 53-69). New York: Springer.

Bond, G. R., \& Kukla, M. (2011). Is job tenure brief in individual placement and support (IPS) employment programs? Psychiatric Services, 62(8), 950-953.

Borzaga C, Santuari A (2000). Social Enterprises in Italy: The experience of social co-operatives. Working paper 15, Institute for Development Studies of Non Profit Enterprises. Retrivered from http://eprints.biblio.unitn.it/175/1/wp15.pdf .

Broom, D. H., D’Souza, R. M., Strazdins, L., Butterworth, P., Parslow, R., \& Rodges, B. (2006). The lesser evil: Bad jobs or unemployment? A survey of mid-aged Australians. Social Science \& Medicine, 63(3), 575-586.

Canadian Mental Health Association (2002). Working well: An employer's guide to hiring and retaining people with mental illness. Ontario: Canadian Mental Health Association.

Corbière, M., Brouwers, E., Lanctôt, N., \& van Weeghel, J. (2014b). Employment specialist competencies for supported employment programs. Journal of Occupational Rehabilitation, 24(3), 484-497.

Corbière, M., Lanctôt, N., Lecomte, T., Latimer, E., Goering, P., Kirsh, B., Goldner, E. M., Reinharz, D., Menear, M., Mizevich, J., \& Kamagiannis, T. (2010). A Pan-Canadian evaluation of supported employment programs dedicated to people with severe mental disorders. Community Mental Health Journal, 46, 44-55.

Corbière, M., \& Lecomte, T. (2009). Vocational services offered to people with severe mental illness. Journal of mental Health, 18(1), 38-50.

Corbière, M., Lesage, A., Villeneuve, K., \& Mercier, C. (2006). Le maintien en emploi de personnes souffrant d'une maladie mentale. Santé Mentale au Québec, 31(2), 215-235. 
Corbière, M., Villotti, P., Lecomte, T., Bond, G. R., Lesage, A., \& Goldner, E. M. (2014a). Work accommodations and natural supports for maintaining employment. Psychiatric Rehabilitation Journal, 37(2), 90-98.

Corbière, M., Villotti, P., Toth, K., \& Waghorn, G. (2014c). Disclosure of a mental disorder in the workplace and work accommodations: Two factors associated with job tenure of people with severe mental disorders. Encéphale, 40(S2), 91-102.

D’Amours, M. (2002). Économie sociale au Québec. Vers un clivage entre entreprise collective et action communautaire. Revue internationale de l'économie sociale, 284, 31-44.

Fossey, E., \& Harvey, C. (2010). Finding and sustaining employment: a qualitative meta-synthesis of mental health consumer views. Canadian Journal of Occupational Therapy, 77(5), 303-314.

Frado L (1993). Diversity Works: Accommodations in the Workplace for People with Mental Illness. Canadian Mental Health Association, National office. Retrieved from https://calgary.cmha.ca/download.php?docid=39 .

Kirsh, B. (2000). Work, workers, and workplaces: a qualitative analysis of narratives of mental health consumers. Journal of Rehabilitation, 66(4), 24-30.

Kirsh, B., Cockburn, L., \& Gewurtz, R. (2005). Best practice in occupational therapy: Program characteristics that influence vocational outcomes for people with serious mental illnesses. The Canadian Journal of Occupational Therapy, 75(5), 265-279.

Lanctôt, N., Bergeron-Brossard, P., Sanquirgo, N., \& Corbière, M. (2013). Causal attributions of job loss among people with psychiatric disabilities. Psychiatric Rehabilitation Journal, 36(3), 146-152.

Lanctôt, N., Corbière, M., \& Durand, M. J. (2012). Job tenure and quality of work life of people with psychiatric disabilities working in social enterprises. Journal of Vocational Rehabilitation, 37(1), 39-48.

Leufstadius, C., Eklund, M., \& Erlandsson, L. K. (2009). Meaningfulness in work. Experiences among employed individuals with persistent mental illness. 
Work: A Journal of Prevention, Assessment and Rehabilitation, 34(1), 21-32.

MacDonald-Wilson K, Rogers E, Massaro J, Lyass A, Crean T (2002). An investigation of reasonable workplace accommodations for people with psychiatric disabilities: Quantitative findings from a multi-site study. Community Mental Health Journal,38(1): 35-50.

MacDonald-Wilson, K., Rogers, E., \& Massaro, J. (2003). Identifying functional limitations in work for people with psychiatric disabilities. Journal of Vocational Rehabilitation, 18, 15-24.

McDowell, C., \& Fossey, E. (2014). Workplace accommodations for people with mental illness: A scoping review. Journal of Occupational Rehabilitation, 25(1), 197-206. doi: 10.1007/s10926-014-9514-y .

McGurk, S. R., Mueser, K. T., Harvey, P. D., LaPuglia, R., \& Marder, J. (2003). Cognitive and clinical predictors of work outcome in clients with SMI in supported employment. Psychiatric Services, 54, 1129-1135.

Mueser, K., \& McGurk, S. (2014). Supported employment for persons with serious mental illness: Current status and future directions. L'Encephale, 40(S2), S45-S56.

Mueser, K. T., Salyers, M. P., \& Mueser, P. R. (2001). A prospective analysis of work in schizophrenia. Schizophrenia Bulletin, 27, 281-296.

Paluch, T., Fossey, E., \& Harvey, C. (2012). Social firms: building cross-sectoral partnerships to create employment opportunity and supportive workplaces for people with mental illness. Work: A Journal of Prevention, Assessment and Rehabilitation, 43(1), 63-75.

Payne, M. (2005). Modern social work theory (3rd ed.). Houndmills: Palgrave Macmillan.

Roulstone, A., \& Warren, J. (2005). Applying a barriers approach to monitoring disabled people's employment: Implications for the Disability Discrimination Act. Disability \& Society, 21(2), 115-131. 
Schultz, I. Z., Krupa, T., \& Rogers, E. S. (2011). Best practices in accommodating and retaining persons with mental health disabilities at work: Answered and unanswered questions. In I. Z. Schultz \& E. S. Rogers (Eds.), Work accommodation and retention in mental health (pp. 445-461). New York: Springer.

Solovieva, T. I., Dowler, D. L., \& Walls, R. T. (2011). Employer benefits from making workplace accommodations. Disability and Health Journal, 4, 39-45.

Svanberg J, Gumley A, Wilson A (2010). How do social firms contribute to recovery from mental illness? A qualitative study. Clinical Psychology and Psychotherapy. doi: 10.1002/cpp.681 .

Tsang, H., Ng, B. C., \& Chiu, FPF (2002). Job profiles of people with severe mental illness: Implication for rehabilitation. International Journal of Rehabilitation Research, 25, 189-196.

Tsang, H. W., Leung, A. Y., Chung, R. C., Bell, M., \& Cheung, W.-M. (2010). Review on vocational predictors: a systematic review of predictors of vocational outcomes among individuals with schizophrenia: an update since 1998. Australian and New Zealand Journal of Psychiatry, 44, 495-504.

Vanhala, L. (2006). Fighting discrimination through litigation in the UK: the social model of disability and the EU anti-discrimination directive. Disability \& Society, 21(5), 551-565.

Villotti P, Corbière M, Zaniboni S, Fraccaroli F (2012). Individual and environmental factors related to job satisfaction in people with severe mental illness employed in social enterprises. WORK: A Journal of Prevention, Assessment, \& Rehabilitation, 43(1): 33-41.

Villotti, P., Zaniboni, S., \& Fraccaroli, F. (2014). Les entreprises à économie sociale en Italie. L'Encephale, 40(S2), S57-S65.

Wehman, P. (2003). Workplace inclusion: Persons with disabilities and coworkers working together. Journal of Vocational Rehabilitation, 18, 131-141.

Wewiorski, N. J., \& Fabian, E. S. (2004). Association between demographic and diagnostic factors and employment outcomes for people with psychiatric 
disabilities: A synthesis of recent research. Mental Health Services Research, 6(1), 9-21.

Williams A, Fossey E, Harvey C (2012). Social firms: sustainable employment for people with mental illness. Work: A Journal of Prevention, Assessment, \& Rehabilitation, 43:53-62.

Williams, A. E., Fossey, E., Corbiere, M., Paluch, T., \& Harvey, C. (2016). Making a difference to job tenure for people with severe mental illnesses: An integrative literature review. Australian Occupational Therapy Journal, 63, 6585.

Williams M, Sabata D, Zolna J (2006). User needs evaluation of workplace accommodations. Work: A Journal of Prevention, Assessment, \& Rehabilitation, 27(4):355-62.

Zaniboni, S., Fraccaroli, F., Villotti, P., \& Corbière, M. (2011). Working plans of people with mental disorders employed in Italian Social Enterprises. Psychiatric Rehabilitation Journal, 35(1), 55-58. 